Original Article

\title{
A comparison of the balance and gait function between children with Down syndrome and typically developing children
}

\author{
Hee-Kyoung Jung, PT, MSc ${ }^{1)}$, EunJung Chung, PT, PhD²), Byoung-Hee Lee, PT, PhD** \\ 1) Graduate School of Physical Therapy, Sahmyook University, Republic of Korea \\ 2) Department of Physical Therapy, Andong Science College, Republic of Korea \\ 3) Department of Physical Therapy, Sahmyook University: 815 Hwarang-ro, Nowon-gu, Seoul 01795 , \\ Republic of Korea
}

\begin{abstract}
Purpose] The purpose of this study was to compare the balance and gait functions of children with Down syndrome and typically developing children according to age. [Subjects and Methods] The subjects were 16 children with Down syndrome and 20 children with typical development. The one leg standing test, Romberg's test (open eyes/closed eyes), sharpened Romberg's (open eyes/closed eyes), functional reaching test and GAITRite were used for this study in order to measure the children's balance and gait function. [Results] The results of this study showed that static-dynamic balance ability, spatio-temporal gait parameters and quality of life were statistically and significantly different in Down syndrome children compared to typically developing children. [Conclusion] These results suggest that the balance and gait ability of typically developing children improves during growth, whereas those of children with Down syndrome remain low despite independent gait. Therefore, constant therapeutic intervention for balance and gait function is necessary after independent gait development in Down syndrome children. Key words: Down syndrome, Balance, Gait
\end{abstract}

(This article was submitted Aug. 31, 2016, and was accepted Oct. 17, 2016)

\section{INTRODUCTION}

Down syndrome is caused by an abnormal extra presence of the 21 st chromosome ${ }^{1,2)}$. Due to the resulting nonhereditary mental retardation, several problems arise such as developmental delay, hearing problems, vision problems and respiratory dysfunctions $^{1-3)}$. In particular, disabilities related to motor function are extensive, for example abnormal gait patterns and postural control, dilatory response to environment alteration, lack of coordination, and concurrent contraction of agonists and antagonists ${ }^{4}$. Juvenile motor development is delayed because muscle activation patterns are unstable and not well-organized and thus, motor dysfunction leads to muscle dystonia ${ }^{5,6)}$.

Motor dysfunction in childhood leads to limited physical activity and lack of activity experience, in addition to developmental delay of the senses and perception, concept formation of movement, and social ability. Equilibrium is an ability that keeps the center of gravity within the base of support with a limited amount of sway, thus it is essential for postural control and activity ${ }^{7)}$. The clinical ability to control equilibrium is crucial for children. Above all, postural balance control of standing and sitting is important for the improvement of life quality through activities of daily living ${ }^{8}$. Balance is one of the major factors that affect the safety and independence skills of Down syndrome children, and is the hardest function to acquire. The gross motor skills of Down syndrome children are consistently low compared to those of normal children, and balance shows the largest difference. Gait is an important indicator of motor development in humans. It can affect cognition, sociality, and complicated motor abilities such as running and jumping ${ }^{9}$. Independent walking in the development process of

*Corresponding author. Byoung-Hee Lee (E-mail: 3679@syu.ac.kr)

(C2017 The Society of Physical Therapy Science. Published by IPEC Inc.

This is an open-access article distributed under the terms of the Creative Commons Attribution Non-Commercial No Derivatives (by-nc-nd) License $<$ http://creativecommons.org/licenses/by-nc-nd/4.0/>. 
children depends on appropriate balance and effective driving force. When the non-supporting foot uses most of its power as the driving force, it is important that the supporting foot maintains the balance in early independent gait ${ }^{10}$.

Compared to typically developing children, Down syndrome children experience a delay of 12 to 18 months for independent gait and approximately $80 \%$ of Down syndrome patients experience gait malfunctions due to insufficient strength ${ }^{9}$. As a result, there is a difference in their gait patterns compared to typically developing children. Especially, the biological characteristics of Down syndrome associated with muscle hypotonia, excessive ligament laxity, postural instability, and lack of balance have a negative impact on the normal development of gait $^{1,5,6)}$.

Balance and gait play a critical role in activities of daily living for humans, and can be affected by interior or exterior factors as the subject becomes older ${ }^{11}$. Movement is limited due to the dysfunction of balance and gait. Additionally, life quality and participation in daily living are affected ${ }^{12)}$.

Therefore, in this study, we measured the balance ability and gait function of Down syndrome children and typically developing children to compare and analyze the two groups. The collected information provides the basic data necessary to develop an intervention program for the improvement of balance and gait function. In addition, this study evaluated and established goals that can be helpful for therapists, Down syndrome children, and their parents.

\section{SUBJECTS AND METHODS}

The subjects were 16 Down syndrome children and 20 children with typical development, for a total of 36 children. Participants were divided according to age into 2 groups: children before school-age were 4-7 years old and school-aged children were 8-12 years old. The present study was approved by the Sahmyook University Institutional Review Board and the objectives of the study as well as the requirements were explained to the subjects. All participants provided written parental consent, in accordance with the ethical principles of the Declaration of Helsinki.

The inclusion criteria were as follows for Down syndrome children: (1) ability to walk 20 meters without assistance, (2) ability to comply with researchers' and guardians' instructions, and (3) permission from parents for the study. The exclusion criteria were as follows: (1) visual or auditory problems, and (2) a major history of disease or surgery.

The inclusion criteria were as follows for typically developing children: (1) ability to comply with researchers' and guardians' instructions, and (2) permission from the parents for the study. The exclusion criteria were as follows: (1) visual or auditory problems, and (2) musculoskeletal disease or taking medicine related to musculoskeletal illness within the last 6 months. Children with a history of surgery were also excluded.

Static balance ability was measured using the One Leg Standing Test (OLST), Romberg's Test (RT) and the Sharpened Romberg's Test (SRT). The OLST was used to assess static balance. Participants were instructed to keep their balance on the non-dominant leg with eyes open. The elapsed time before the contra-lateral foot touched the ground was measured in seconds using a stopwatch ${ }^{13)}$. Romberg's test is a static balance test. Subjects were required to stand with their feet together, eyes open or closed, with hands by their sides for a period of time, usually a minute. The sharpened Romberg's test was conducted with the dominant foot positioned behind the non-dominant foot to form a straight line with the toes behind the heel and both arms crossed in a natural pose. The functional reaching test (FRT) is a dynamic balance test. Subjects were asked to stand $10 \mathrm{~cm}$ from the wall so that their shoulders were perpendicular to the reach measurement device. Subjects extended their arms horizontally and placed a closed first against the sliding handle ${ }^{14)}$.

Gait function was measured using a GAITRite system (CIR Systems Inc., Havertown, PA, USA). The GAITRite system was used to measure spatiotemporal parameters, including gait velocity, cadence, step length, stride length and step width. The subjects were asked to walk at a comfortable speed, without the use of an assistive device, along a 10-m hallway ${ }^{15}$.

All statistical analyses were performed using SPSS, version 19.0. The general characteristics are presented as frequencies and percentages, with average and standard deviations also provided. The independent t-test was used for the analysis of changes in dependent variables between groups. The significance threshold was set to $\mathrm{p}<0.05$.

\section{RESULTS}

The demographic characteristics of the subjects are shown in Table 1. Thirty-six subjects participated in this study, sixteen males and twenty females. Subjects in the Down syndrome children group and the typically developing children group were similar in terms of age, height, and weight. No significant differences between the general characteristics of the two groups were detected at recruitment.

The one leg standing test, Romberg's test, sharpened Romberg's test of static balance and FRT of dynamic balance showed significant differences in the two groups (Table 2). The velocity, cadence of temporal gait parameters and step length, stride length, and step width of spatial gait parameters also showed significant differences in the two groups. The typically developing children group showed significant differences in Romberg's test with closed eyes, sharpened Romberg's with closed eyes, FRT, step length and stride length during growth. The Down syndrome child group only showed significant differences in cadence during growth. 
Table 1. Characteristics of the participants $(\mathrm{N}=36)$

\begin{tabular}{llcc}
\hline & & $\begin{array}{c}\text { Down syndrome children } \\
(\mathrm{n}=16)\end{array}$ & $\begin{array}{c}\text { Typically developing } \\
\text { children }(\mathrm{n}=20)\end{array}$ \\
\hline Gender & Total & $7(19.4) / 9(25.0)$ & $9(25.0) / 11(30.6)$ \\
Male/Female & Before school-age & $3(8.3) / 6(16.7)$ & $4(11.1) / 5(13.9)$ \\
$(\%)$ & School-aged children & $4(11.1) / 3(8.3)$ & $5(13.9) / 6(16.7)$ \\
Age & Total & $6.8(1.8)$ & $8.0(2.4)$ \\
$(\mathrm{yrs})$ & Before school-age & $5.4(1.0)$ & $5.8(1.2)$ \\
& School-aged children & $8.4(0.8)$ & $9.7(1.3)$ \\
Height & Total & $90.6(26.5)$ & $119.5(20.3)$ \\
$(\mathrm{cm})$ & Before school-age & $79.2(30.0)$ & $101.6(10.7)$ \\
& School-aged children & $105.3(10.7)$ & $134.2(13.0)$ \\
Weight & Total & $15.4(6.3)$ & $26.3(11.1)$ \\
$(\mathrm{kg})$ & Before school-age & $11.6(4.5)$ & $17.1(4.4)$ \\
& School-aged children & $20.1(4.8)$ & $33.8(9.0)$ \\
\hline
\end{tabular}

n (\%) or mean (SD); Total: children aged 4 to 12 ; before school-age: 4-7 years old; school-aged children:

$8-12$ years old

\section{DISCUSSION}

Ability to keep the center of gravity within the base of support and balance is critical for ADL, mobility and performance for children, and thus is an essential requisite for all kinds of exercise. Therefore, functional enhancement with the improvement of balance performance is expected ${ }^{16)}$.

This study was performed to compare static balance (one leg standing test, Romberg's test and sharpened Romberg's) and dynamic balance (functional reaching test) between Down syndrome children and typically developing children. In this study, balance ability analysis was performed by dividing the subjects into a preschool age group and a school age group as the balance ability changes during growth ${ }^{11)}$. The Down syndrome children had significant differences in all areas of balance ability in comparison with typically developing children $(p<0.05)$. Typically developing children showed higher balance ability than the Down syndrome children. This corresponds with the following previous study results: the static-dynamic balance of Down syndrome children showed more differences than other motor skills compared to typically developing children and Down syndrome children lack static balance ability ${ }^{17}$. The reason for this is that their muscle reaction velocity is significantly slower compared to their peers, and there is much difficulty with vision, motor control, and agility ${ }^{1,3-6)}$.

The one leg standing test for Down syndrome children ( 0.63 second) lasted for a shorter period than for typically developing children (45.54 seconds). This is because the proprioception sense in Down syndrome children is decreased and they tend to have a wider basal surface due to the low stability from the narrow basal surface.

Typically developing children of all ages maintained their balance with eyes closed for a shorter period than with eyes open in the Romberg's and Sharpened Romberg's tests. The Down syndrome children also had similar results. This indicates that postural disturbance is larger when standing with eyes closed, and decreases when visual feedback about the position is provided, increasing visual dependence ${ }^{18)}$.

In the Romberg's test (RT) (eyes open, EO: $58.65 \mathrm{sec}$, eyes closed, EC: $52.95 \mathrm{sec}$ ), normal children of all ages maintained their balance for a longer period of time than in the Sharpened Romberg's test (SRT) (eyes open: 50.35 sec, eyes closed: 40.35 $\mathrm{sec}$ ), showing that SRT requires higher balance ability than RT. Down syndrome children of all ages showed a markedly low balance ability in SRT (EC) compared to typically developing children of all ages. This is because SRT requires a higher level of balance ability than RT. SRT (EC), even with visual feedback, is a difficult task for Down syndrome children with low balance ability $(0.00 \mathrm{sec})$.

When comparing the balance ability of typically developing children of preschool age and school age, there was a significant difference in the Romberg's test (eyes closed), Sharpened Romberg's test (eyes closed) and functional reaching test $(\mathrm{p}<0.05)$. These results show that the balance ability of typically developing children improves with growth. However, when comparing the balance ability of Down syndrome children of preschool age and school age, there was no significant difference in all 6 fields, and both groups displayed low balance ability. These results show that the balance ability of typically developing children improves with growth, but that of Down syndrome children remains low despite the acquisition of independent gait. Therefore, constant therapeutic intervention for balance after independent gait achievement is necessary.

Gait is the most important activity among human movement as it is the basis of all movements in daily life, and normal gait development in childhood is significant in the aspect of motor development. In particular, gait in Down syndrome children is a necessary physical activity to experience the surrounding environment and improve health ${ }^{19)}$. In this study, gait ability analysis was conducted using GAITRite for Down syndrome children and typically developing children. The gait 
Table 2. Comparison of the balance and gait function $(\mathrm{N}=36)$

\begin{tabular}{|c|c|c|c|}
\hline & & $\begin{array}{l}\text { Down syndrome } \\
\text { children }(n=16)\end{array}$ & $\begin{array}{l}\text { Typically developing } \\
\text { children }(n=20)\end{array}$ \\
\hline \multicolumn{4}{|l|}{ Balance function } \\
\hline \multirow{3}{*}{$\begin{array}{l}\text { OLST } \\
\text { (s) }\end{array}$} & Total & $0.6(1.1)$ & $45.5(17.1)^{*}$ \\
\hline & Before school-age & $0.2(0.5)$ & $38.1(20.8)^{*}$ \\
\hline & School-aged children & $1.3(1.4)$ & $51.6(10.8)^{*}$ \\
\hline \multirow{3}{*}{$\begin{array}{l}\mathrm{RT}(\mathrm{EO}) \\
(\mathrm{s})\end{array}$} & Total & $0.6(2.0)$ & $58.7(6.0)^{*}$ \\
\hline & Before school-age & $0.1(0.3)$ & $57.0(9.0)^{*}$ \\
\hline & School-aged children & $1.1(3.0)$ & $60.0(0.0)^{\ddagger}$ \\
\hline \multirow{3}{*}{$\begin{array}{l}\mathrm{RT}(\mathrm{EC}) \\
(\mathrm{s})\end{array}$} & Total & $0.6(2.3)$ & $53.0(13.5)^{\star}$ \\
\hline & Before school-age & $0.0(0.0)$ & $44.6(17.0)^{:}$ \\
\hline & School-aged children & $1.3(3.4)$ & $59.8(0.60)^{*}, \$$ \\
\hline \multirow{3}{*}{$\begin{array}{l}\text { SRT(EO) } \\
(s)\end{array}$} & Total & $0.5(2.0)$ & $50.4(14.2)^{\ddagger}$ \\
\hline & Before school-age & $0.0(0.0)$ & $44.4(16.1)^{*}$ \\
\hline & School-aged children & $1.1(3.0)$ & $55.2(10.8)^{\ddagger}$ \\
\hline \multirow{3}{*}{$\begin{array}{l}\text { SRT(EC) } \\
(\mathrm{s})\end{array}$} & Total & $0.0(0.0)$ & $40.4(21.8)^{*}$ \\
\hline & Before school-age & $0.0(0.0)$ & $26.4(19.4)^{*}$ \\
\hline & School-aged children & $0.0(0.0)$ & $51.7(16.7)^{* *}, \$$ \\
\hline \multirow{3}{*}{$\begin{array}{l}\text { FRT } \\
(\mathrm{cm})\end{array}$} & Total & $12.0(3.5)$ & $25.2(6.4)^{\ddagger}$ \\
\hline & Before school-age & $10.9(2.5)$ & $20.9(5.6)^{\ddagger}$ \\
\hline & School-aged children & $13.3(4.2)$ & $28.8(4.8)^{* *}, \ddagger$ \\
\hline \multicolumn{4}{|l|}{ Gait function } \\
\hline \multirow[t]{3}{*}{ Velocity $(\mathrm{cm} / \mathrm{s})$} & Total & $85.8(16.0)$ & $103.23(25.89)^{\dagger}$ \\
\hline & Before school-age & $90.1(11.9)$ & $91.43(19.06)$ \\
\hline & School-aged children & $80.3(19.8)$ & $112.89(27.48)^{\dagger}$ \\
\hline \multirow{3}{*}{$\begin{array}{l}\text { Cadence } \\
\text { (steps/mim) }\end{array}$} & Total & $154.8(30.1)$ & $131.6(18.2)^{*}$ \\
\hline & Before school-age & $171.2(28.3)$ & $137.7(16.7)^{*}$ \\
\hline & School-aged children & $133.7(16.7)^{* *}$ & $126.5(18.5)$ \\
\hline \multirow{3}{*}{$\begin{array}{l}\text { Step length } \\
(\mathrm{cm})\end{array}$} & Total & $33.6(6.7)$ & $47.5(10.9)^{*}$ \\
\hline & Before school-age & $31.8(3.7)$ & $40.1(7.1)^{*}$ \\
\hline & School-aged children & $35.9(9.1)$ & $53.6(9.8)^{* *}, \$$ \\
\hline \multirow{3}{*}{$\begin{array}{l}\text { Stride length } \\
(\mathrm{cm})\end{array}$} & Total & $67.4(12.1)$ & $95.1(22.4)^{*}$ \\
\hline & Before school-age & $63.8(5.9)$ & $80.5(14.4)^{*}$ \\
\hline & School-aged children & $72.1(16.7)$ & $107.1(21.0)^{* *}, *$ \\
\hline \multirow{3}{*}{$\begin{array}{l}\text { Step width } \\
(\mathrm{cm})\end{array}$} & Total & $10.9(2.7)$ & $8.8(2.1)^{*}$ \\
\hline & Before school-age & $11.2(2.7)$ & $8.4(1.7)^{\dagger}$ \\
\hline & School-aged children & $10.6(2.5)$ & $9.1(2.4)$ \\
\hline \multicolumn{4}{|c|}{$\begin{array}{l}\text { Values are means (SD). Total: children aged } 4 \text { to } 12 \text {; Before school-age: } 4-7 \text { years old; School-aged } \\
\text { children: } 8-12 \text { years old; OLST: one leg standing test; RT: Romberg test; SRT: Sharpened Romberg } \\
\text { test; FRT: functional reaching test; EO: Eyes Open; EC: Eyes Closed; }{ }^{*}<<0.05 \text { compared with the Be- } \\
\text { fore school-age and School-aged children; } * * \text { p }<0.01 \text { compared with the Before school-age and School- } \\
\text { aged children; } \dagger p<0.05 \text { from mean between the two groups; } \$ \mathrm{p}<0.01 \text { from mean between the two } \\
\text { groups }\end{array}$} \\
\hline
\end{tabular}

analysis was performed by dividing the subjects into a preschool age group and a school age group as the gait pattern changes during growth ${ }^{11}$.

In this study, the Down syndrome children had a shorter stride and stride length and a wider stride interval among the spatial gait variables. The abnormal splayfooted gait with decreased stride width and wide stride interval is because of instability due to weaker lower extremity strength and a lower balance function ${ }^{20}$. Stride length is related to the leg length. Down syndrome causes physical imbalance and growth delays due to nutritional imbalance and movement restrictions. The stride length of Down syndrome children is $45.94 \mathrm{~cm}$ compared to $58.30 \mathrm{~cm}$ for typically developing children, indicating a short stride length for Down syndrome children. In the present study, the results showed that the legs of typically developing children grew longer as they approached school age, resulting in increased stride length $(\mathrm{p}<0.05)$. Stride and stride length 
are also related to a child's balance ability in addition to leg length. Down syndrome children have less balance compared to typically developing children ${ }^{21)}$ so they are unable to position their feet far apart between the terminal swing phase and the initial stance phase and instead position them close together, resulting in a shorter stride and stride length. Short stride and stride length result in slow gait velocity and high cadence. The pre-school aged Down syndrome children showed significant differences in step width $(11.17 \mathrm{~cm})$ in comparison with typically developing children $(8.38 \mathrm{~cm})(\mathrm{p}<0.05)$. This is because Down syndrome children tend to have a wider basal surface due to low stability with a narrow basal surface ${ }^{21)}$.

Most of the parents of the Down syndrome children do not regard physical therapy intervention as important after the children achieve independent gait. According to this study result, however, Down syndrome children consistently show abnormal gait patterns compared to typically developing children, and the balance ability is markedly decreased as well. The reduced balance and gait ability limits their ability to handle sudden environmental changes and participation in daily life. As mentioned previously, continuous physical therapy intervention for balance ability improvement is necessary even after independent gait, so the children can increase their participation in daily life and handle sudden changes in their environment.

The results of the gait variables proposed in this study reveal the extent of the abnormal gait in Down syndrome children, and can be used as basic data in developing gait intervention programs and setting treatment goals.

\section{ACKNOWLEDGEMENT}

This paper was supported by the Health Sciences for Specialization Project Fund of the Sahmyook University in 2016.

\section{REFERENCES}

1) Basil JS, Santoro SL, Martin LJ, et al.: Retrospective study of obesity in children with Down syndrome. J Pediatr, 2016, 173: 143-148. [Medline] [CrossRef]

2) Marchal JP, Maurice-Stam H, van Trotsenburg AS, et al.: Mothers and fathers of young Dutch adolescents with Down syndrome: health related quality of life and family functioning. Res Dev Disabil, 2016, 59: 359-369. [Medline] [CrossRef]

3) Roizen NJ, Magyar CI, Kuschner ES, et al.: A community cross-sectional survey of medical problems in 440 children with Down syndrome in New York State. J Pediatr, 2014, 164: 871-875. [Medline] [CrossRef]

4) Chen HL, Yeh CF, Howe TH: Postural control during standing reach in children with Down syndrome. Res Dev Disabil, 2015, 38: 345-351. [Medline] [CrossRef]

5) Gontijo AP, Mancini MC, Silva PL, et al.: Changes in lower limb co-contraction and stiffness by toddlers with Down syndrome and toddlers with typical development during the acquisition of independent gait. Hum Mov Sci, 2008, 27: 610-621. [Medline] [CrossRef]

6) Chang CL, Kubo M, Ulrich BD: Emergence of neuromuscular patterns during walking in toddlers with typical development and with Down syndrome. Hum Mov Sci, 2009, 28: 283-296. [Medline] [CrossRef]

7) Nichols DS, Glenn TM, Hutchinson KJ: Changes in the mean center of balance during balance testing in young adults. Phys Ther, 1995, 75: 699-706. [Medline]

8) Carlberg EB, Hadders-Algra M: Postural dysfunction in children with cerebral palsy: some implications for therapeutic guidance. Neural Plast, 2005, 12: 221-228, discussion 263-272. [Medline] [CrossRef]

9) Ulrich DA, Ulrich BD, Angulo-Kinzler RM, et al.: Treadmill training of infants with Down syndrome: evidence-based developmental outcomes. Pediatrics, 2001, 108: E84. [Medline] [CrossRef]

10) Ricken AX, Savelsbergh GJ, Bennett SJ: Coordinating degrees of freedom during interceptive actions in children. Exp Brain Res, 2004, 156: 415-421. [Medline] [CrossRef]

11) Day SM, Strauss DJ, Shavelle RM, et al.: Mortality and causes of death in persons with Down syndrome in California. Dev Med Child Neurol, 2005, 47: 171-176. [Medline] [CrossRef]

12) Davis E, Waters E, Mackinnon A, et al.: Paediatric quality of life instruments: a review of the impact of the conceptual framework on outcomes. Dev Med Child Neurol, 2006, 48: 311-318. [Medline] [CrossRef]

13) Vellas BJ, Rubenstein LZ, Ousset PJ, et al.: One-leg standing balance and functional status in a population of 512 community-living elderly persons. Aging (Milano), 1997, 9: 95-98. [Medline]

14) Duncan PW, Weiner DK, Chandler J, et al.: Functional reach: a new clinical measure of balance. J Gerontol, 1990, 45: M192-M197. [Medline] [CrossRef]

15) McDonough AL, Batavia M, Chen FC, et al.: The validity and reliability of the GAITRite system's measurements: a preliminary evaluation. Arch Phys Med Rehabil, 2001, 82: 419-425. [Medline] [CrossRef]

16) Ferdjallah M, Harris GF, Smith P, et al.: Analysis of postural control synergies during quiet standing in healthy children and children with cerebral palsy. Clin Biomech (Bristol, Avon), 2002, 17: 203-210. [Medline] [CrossRef]

17) Galli M, Rigoldi C, Brunner R, et al.: Joint stiffness and gait pattern evaluation in children with Down syndrome. Gait Posture, 2008, 28: 502-506. [Medline] [CrossRef]

18) Rose J, Wolff DR, Jones VK, et al.: Postural balance in children with cerebral palsy. Dev Med Child Neurol, 2002, 44: 58-63. [Medline] [CrossRef]

19) Draheim CC, McCubbin JA, Williams DP: Differences in cardiovascular disease risk between nondiabetic adults with mental retardation with and without Down syndrome. Am J Ment Retard, 2002, 107: 201-211. [Medline] [CrossRef]

20) Kubo M, Ulrich B: Coordination of pelvis-HAT (head, arms and trunk) in anterior-posterior and medio-lateral directions during treadmill gait in preadolescents with/without Down syndrome. Gait Posture, 2006, 23: 512-518. [Medline] [CrossRef]

21) Agiovlasitis S, McCubbin JA, Yun J, et al.: Effects of Down syndrome on three-dimensional motion during walking at different speeds. Gait Posture, 2009, 30: 345-350. [Medline] [CrossRef] 